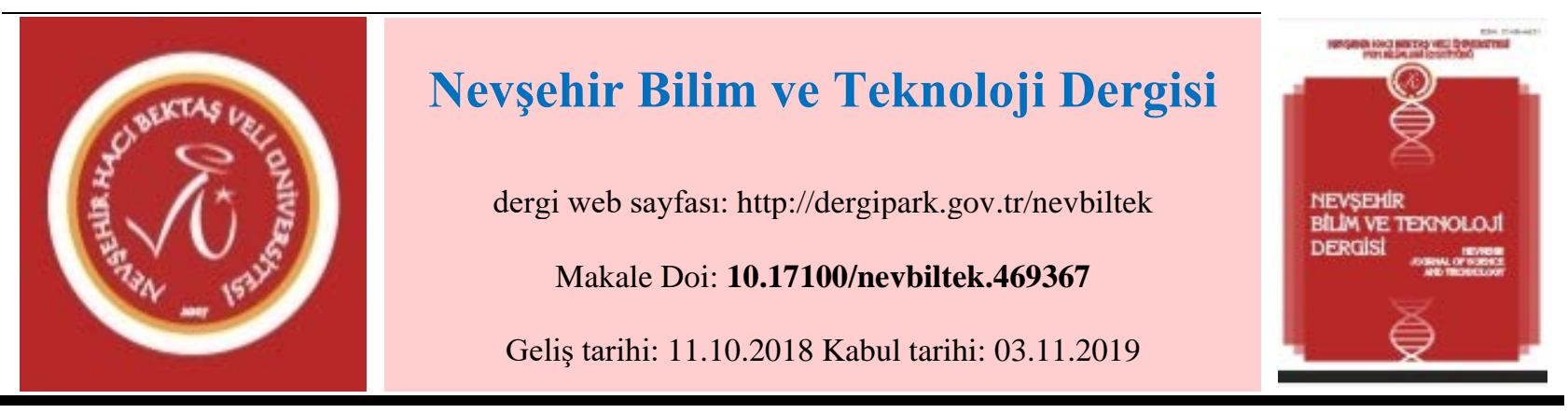

\title{
Rize Kentsel Kıyı Şeridinin Kullanıcı Memnuniyetinin Belirlenmesi*
}

\author{
Banu BEKCI' ${ }^{1}$, Merve ÜÇOK ${ }^{2}$, Hasan YILMAZ ${ }^{3}$ \\ ${ }^{1,2}$ Recep Tayyip Erdoğan Üniversitesi, Güzel Sanatlar, Tasarım ve Mimarlık Fakültesi, Peyzaj Mimarlı̆ğ Bölümü, Rize \\ ${ }^{1}$ ORCID ID: 0000-0003-1789-535X \\ ${ }^{2}$ ORCID ID: 0000-0002-3246-6302 \\ ${ }^{3}$ AtatürkÜniversitesi, Mimarlık ve Tasarım Fakültesi, Peyzaj Mimarlığı Bölümü, Erzurum \\ ${ }^{3}$ ORCID ID: 0000-0003-3768-4760
}

$\ddot{O} \mathbf{z}$

Kıyı alanları ve sahil şeritleri bireylerin artan rekreasyonel ihtiyaçlarına cevap verecek önemli doğal kaynaklardır. Bu alanlar kolay ulaşılabilirliği, zengin kaynak potansiyeline sahip olması ve bireyler üzerindeki psikolojik etkisi nedeniyle yerleşim ve dinlenme alanı olarak tercih edilmektedir. Linear bir yapıya sahip olan sahil şeritleri; peyzajların, dokuların ve bu silüetin içerisine yayılmış rekreasyonel alanların mekânsal sürekliliğini sağlamaktadır. Karadeniz Bölgesi’nin mevcut topoğrafyasının eğimli olmasından doğan güçlüklerden dolayı sahil şeridinin rekreasyonel kullanım alanının önemi artmakta, açık alan ihtiyacının karşılanması yoğun talep görmektedir. Bu çalışmada Rize ili merkez bölgesi kıyı şeridinde mevcut rekreasyonel alanlardaki kullanıcı talepleri ve memnuniyet durumları ele alınmış olup, alan kullanıcılarına anketler yapılarak kullanıcı memnuniyetleri ve talepleri sorgulanmıştır. Elde edilen sonuçlara göre rekreasyonel alanların karakteristikleri Altman and Zube (1989)'un geliştirmiş olduğu kriterler dikkate alınıp incelendiğinde kullanıcıların; aktivite ve kullanım kriterinde \%38'lik oranla spor yapmayı, ulaşılabilirlik kriterinde $\% 78$ 'lik oranla yürümeyi, konfor ve imaj kriterinde $\% 42$ 'lik oranla temiz hava almayı, sosyallik kriterinde $\% 42$ 'lik oranla aile veya arkadaş gruplarıyla etkinlik gerçekleştirmeyi tercih ettiği görülmüştür. Rize kentsel kıyı şeridini kullanan 190 kullanıcı (\%44 kadın, \%56 erkek), r=,152* alanı temiz bulmamakta $\mathrm{r}=, 257^{* *}$ alanın iyi yönetildiğini düşünmemekte, $\mathrm{r}=, 262^{* *} ; \mathrm{r}=, 146^{*} ; \mathrm{r}=, 217^{* *}$ çocuk oyun alanları, donatı elemanları ve açık yeşil alanları yetersiz bulmakta, $\mathrm{r}=, 149 *$ bitkisel tasarımları işlevsiz bulmakla birlikte $\mathrm{r}=, 235^{* *}$ kentin denize bakan ön cephesindeki binaların sahil görüntüsünü kapatması nedeniyle Sahil Parkı'nı kent parkları ile ilişkili bulmamaktadır. Elde edilen sonuçlarla birlikte kıyı şeridi rekreasyonel alanlarına yönelik öneriler geliştirilmiştir.

Anahtar Kelimeler: Kıyı şeridi, Rize, rekreasyonel alan, kullanıcı memnuniyeti

\section{Determination of User Satisfaction of Rize Urban Coast Line}

\begin{abstract}
Coastal areas and shorelines are important natural resources to meet the increasing recreational needs of individuals. These areas are preferred as residential and recreational areas due to their easy accessibility, their rich resource potential and their psychological effect on the individuals. The coastal strips which have a linear structure help the spatial continuity of landscapes, textures and recreational spaces that extend into this silhouette. Due to the slope of the existing topography of the Black Sea Region, the importance of recreational use of the coastal lane is increasing and the demand for open space is in high demand. In this study, the user demands and satisfaction in the recreational areas in the coastal zone of Rize province central region were discussed and user requests were questioned by making surveys to the users of the area. According to the obtained results, when the criteria of recreational areas developed by Altman and Zube (1989) are considered and examined, it has been seen that it is preferred to perform sports with a rate of $38 \%$ in the criteria of activity and usage, to walk with $78 \%$ in the accessibility criterion, to receive fresh air with a comfort and image criterion with rate of $42 \%$ and to perform activities with family or friends groups in the sociability criterion with $42 \%$. 190 users (44\% female, 56\% male) using the Rize urban shoreline did not find the area of $\mathrm{r}=, 152 *$ clear, $257 * *$ do not think that the area is well managed, $\mathrm{r}$ $=, 262 * * ; r=146 * ; r=, 217 * *$ children playgrounds, accessory elements and open green areas are inadequate, $r=, 149 *$ vegetation designs have no function $\mathrm{r}=, 235 * *$ coastal view of the coastal park is not possible due to the buildings in front of the sea facing the sea, parks. With the results obtained, proposals for recreational areas of coastal strip have been developed.
\end{abstract}

Keywords: Coastline, Rize, recreational area, user satisfaction.

* Makale 1. Uluslararası Teknoloji Bilimleri ve Tasarım Sempozyum'unda sözlü bildiri olarak sunulmuş ve yayınlanmıştır.

Sorumlu yazar e-mail: merve.ucok@erdogan.edu.tr 


\section{Giriş}

Birçok rekreasyonel olanak sunan kent parkları, kolay ulaşılabilen ve bireyin kentin olumsuz etkilerinden kurtulmasına olanak sağlayan önemli kent içi açık alanlardır. Bu anlamda dünya nüfusunun büyük bir çoğunluğunun kentlerde yaşadığı düşünüldüğünde park alanlarının ne denli önemli olduğu görülmektedir. Özellikle kentsel peyzaj içerisinde yer alan yeşil alanlar, insanı doğaya yaklaştırarak kent içerisindeki parklar, bahçeler, gezi alanları ve dinlenme alanları vasıtasıyla insanları doğa ile buluşturmaktadır [1].

Kent parkları, kentin havasını temizlemek, rüzgârı ve gürültüyü filtreleyerek mikro klima etkisi yaratmak gibi çevresel faydalar sunmanın [2] yanı sıra kentte yaşayan bireylere estetik, rekreasyonel, fizyolojik ve ekonomik yararlar da sağlamaktadır [3]. Bu alanlarda insanların içinde bulundukları ortamlardan önemli ölçüde etkilendiği ve daha da önemlisi, içinde bulundukları ortamın mutluluk durumlarını etkilediği bilinmektedir. Bu etkinin nedenleri, esas olarak bu tür ortamları oluşturan mekânsal elemanların ve bileşenlerin özellikleri ve görünüşleridir [4]. Bu nedenle kent parkları kent ekosistem ağının önemli bir parçasını oluşturarak kentin ekosistemine katkı sağlamaktadır. Kent içerisinde yer alan yeşil alanlar hızlı kentleşen toplumların yaşam kaliteleri için stratejik bir önem taşımakta [2] ve sürdürülebilir kentlerin göstergesi olarak kabul edilmektedir. Bazı araştırmalarda, kent parkları ve açık alanlar insanların kendilerini iyi hissettikleri ve fiziksel aktivitelere katılmaya teşvik edildikleri yerler olarak ele alınmaktadır [5]. Günümüz yaşam şartları dikkate alındığında kullanıcıların fiziksel hareket kapasitelerinin azaldığı görülmekte olup araştırmacılara göre, park alanlarının aktif bir şekilde kullanılması halk sağlı̆̆ını ve fiziksel aktivite olanaklarının sıklıkla kullanılmasını olumlu yönde etkileyecektir [6].

Kent içerisinde yer alan park alanları bozulan kentsel dokunun iyileşmesi ve gelişmesi yönünde önemli katkılar sunarken kentin kimlik kazanmasında önemli alan kullanımlarından biri olarak karşımıza çıkmaktadır [7]. Parkların temel işlevi, kullanıcılarını memnun etmektir. Bu nedenle iyi yönetilen parklar kullanıcıların ihtiyaçlarını karşılayan hizmetler sunarak, toplumun her kesimine hitap edip bir nevi toplumda firsat eşitliği sağlamalıdır.

Açık hava rekreasyonu deneyimlerine yönelik ziyaretçi memnuniyet çalışmaları 1960'lı yıllardan beri ilgili literatürde önemli yer bulmaktadır [8]. Rekreasyonel alan kullanıcılarının bu alanlardan fayda sağlayabilmesi için park alanlarından edindikleri deneyimlerden memnun olmaları gerekmektedir. Bu nedenle, kamuya yönelik açık hava rekreasyon yöneticilerinin; halkın ziyaret ettikleri tesislerden ve yararlandıkları hizmetlerden edindikleri memnuniyeti bilmeleri önemlidir [9]. Bu kapsamda birçok çalışma bulunmakla birlikte Onsekiz ve Emür 2008'de yaptığı çalışmada kent parkı kullanıcılarının memnuniyetleri, beklenti ve isteklerinin belirlenmesi parkların hizmet kalitesinin değerlendirilmesinde etkin parametreler olduğunu belirtmiştir [21]. Ayrıca ziyaretçilerin parklara yönelik alg1 ve tercihleri kent parklarının planlama ve tasarım süreçlerini etkin olarak yönlendiren etmenlerdir [10]. Roovers ve ark. [11]'na göre rekreasyon aktivitelerinin açıklanması için kullanıcıların özellikleri çok önemli bir değişkendir. Sosyal sınıf, davranış ve tutumlardaki kültürel farklılıklar da müşteri beklenti ve algılamalarını etkileyebilmektedir [12].

Yaşamı fiziksel ve psikolojik olarak daha rahat kılmak ve ihtiyaçlara daha uygun ortamlar oluşturmak için, kullanıcıların fiziksel, fizyolojik, psikolojik ve sosyal yapısından kaynaklanan ihtiyaçlarını önceden kestirmek ve açık mekânlardan oluşan çevreyi bu ihtiyaçlara göre şekillendirmek gereklidir [13]. Kullanıcılarının beklenti ve memnuniyetlerini daha yüksek kalitedeki alanlarda karşılaması ve rekreasyon deneyimlerinin kalitesini arttırabilmesi için bu alanlara uygun planlama kararlarının alınmasının önemi gittikçe artmaktadır [14]. Bütün bu çalışmalar doğrultusunda ele alınan çalışma alanının rekreasyonel kullanımlarındaki kullanıcı memnuniyetleri ortaya koyularak, tasarımlarda karşılaşılan eksiklikler tespit edilip çeşitli çözüm önerileri geliştirilmiştir. Bu çalışma ile doğal ve kültürel peyzaj potansiyelinin korunarak elde edilen sonuçlarla birlikte çalışma alanının sürdürülebilir gelişimini sağlayıp, rekreasyonel ihtiyaçlarını karşılaması amaçlanmaktadır. 


\section{Materyal ve Metot}

\section{1 Çalışma Alanı}

Çalışma alanı olarak seçilen Rize kentsel kıyı şeridi Sahil Parkı, kent merkezinde yer alan, 41 1'35.06"K enlem, 40³1'35.26"D boylama sahip, kent halkının dinlenme ve rekreasyonel ihtiyacını karşılayan, kullanım bakımından çeşitlilik arz eden, bir rekreasyonel alandır. Çalışma alanı; piknik alanları, kafeteryalar, spor alanları, çocuk oyun alanları, gezinti yolları, oturma birimleri, manzara ve seyir noktaları gibi rekreasyonel faaliyetler açısından $200.000 \mathrm{~m}^{2}$ 'lik yoğun bir kullanım alanına sahiptir (Şekil 1). Bunun yanı sıra yerleşim alanlarının sahil şeridi boyunca konumlanması alanın kullanım yoğunluğunu ve rekreasyonel potansiyelini belirli bir düzeyde tutmaktadır. Rekreasyonel faaliyet çeşitliliklerine göre alanın kullanılmasında, çocuk oyun alanları, oturma birimleri, piknik masaları, çeşmeler, işaret levhaları ve çöp kutuları gibi peyzaj elemanlarına sıklıkla yer verilmiştir.

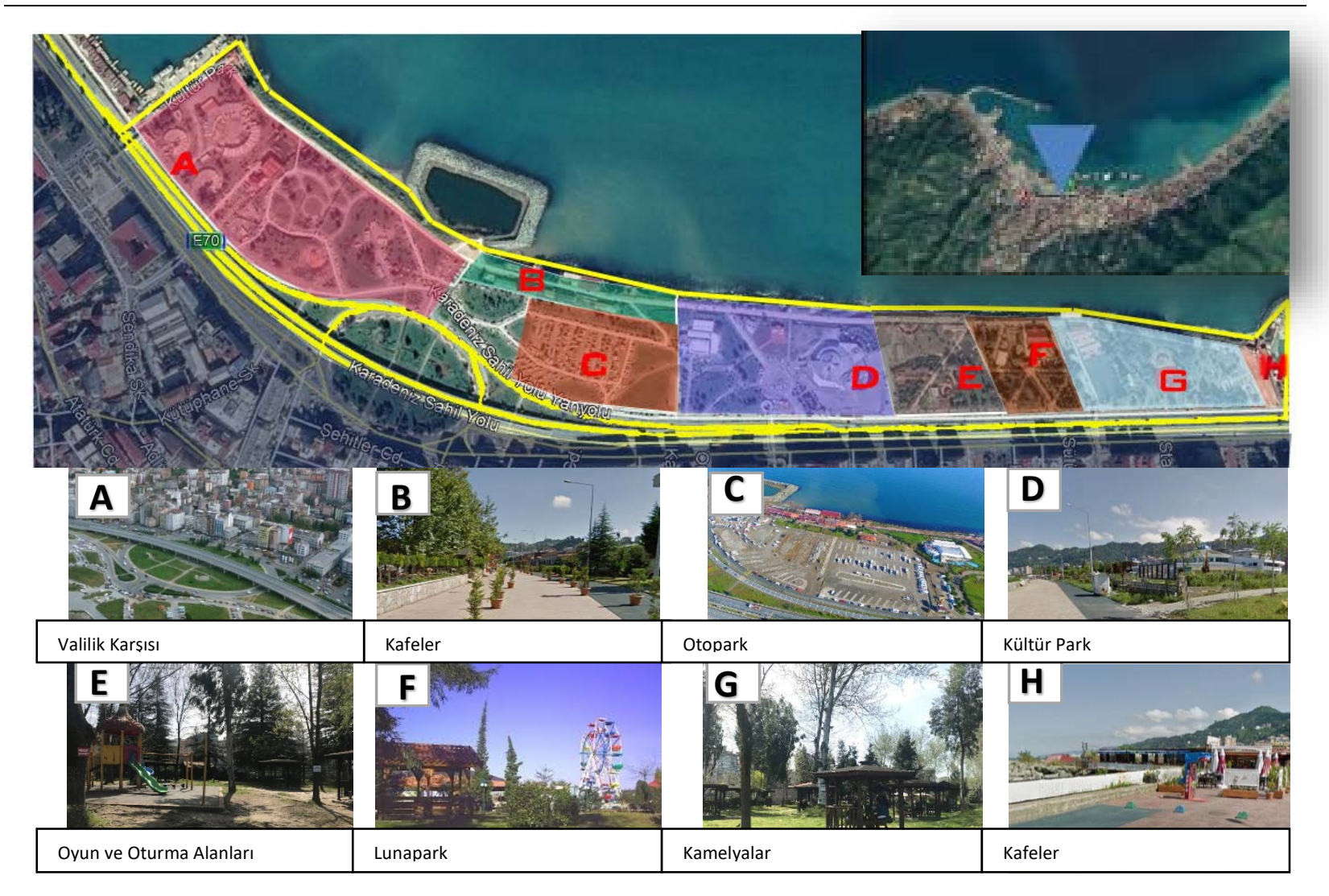

Şekil 1. Çalışma alanı (Rize Sahil Parkı) ve çalışmada kullanılan bölgeler

Çalışmada Rize Belediyesi’nden alınan imar planlarından ve uydu fotoğraflarından yararlanılmıştır. Çalışma alanı içerisinde bölgeler seçilirken kullanıcıların güvenlik ihtiyacı başta olmak üzere ulaşım, rekreasyonel etkinlikler, spor vd. dikkate alınmış olup alan 8 bölgeye ayrılmıştır. Şekil 1. de ele alınan her bir bölge sırayla; (A) Valilik karşısı; Sahil Parkı'nın batı kesiminde yer almakta olup rekreasyonel etkinliklerden uzakta otopark alanına oldukça yakın bir yerdedir. (B) Kafeler; kullanıcıların en kolay ulaşabilecekleri farklı niteliklere sahip dinlenme alanlarından oluşmaktadır. (C) Otopark; geniş bir sert zemin yüzeyine sahip olan bu alan yoğun bir araç sirkülasyonuna sahip olup denize yakın olan kısmında çeşitli restoranlar bulunmaktadır. (D) Kültür Park; sinema ve fuar alanı başta olmak üzere 
çeşitli etkinliklere ev sahipliği yapmaktadır. (E) Oyun ve oturma alanı; doğal alanlara sahip olan bu alanın bitkisel materyal yoğunluğu oldukça fazladır. (F) Lunapark; farklı yaş gruplarına hitap eden çeşitli eğlence araçları gençler ve çocuklu ebeveynler tarafından tercih edilmektedir. (G) Kamelyalar; piknik alanı olarak kullanılmakta, (H) Kafeler; farklı yeme-içme çeşitlerini içerisinde barındırarak kullanıcılara hitap etmektedir.

Tanımlanan bu bölgeler ortak olumlu ve olumsuz özellikleri birlikte üstlenmektedir. Bölgelerin kent merkezine yakınlığı, kentin her noktasından ulaşılabilir olması, farklı rekreasyonel etkinlikleri bünyesinde barındırması, deniz manzarası, yeşil alan yoğunluğunun fazla olması, gece kullanımına uygun olması güçlü yönleri oluştururken, fiziksel çevre tahribatı, çevre kirliliği, kısmi aydınlatma eksikliği, kapalı mekân azlığı, denizin aktif rekreasyonel etkinlikler (kano, yelkenli, yüzme vb.) açısından kullanılmaması, yanlış budanan bitki toplulukları, çocuk oyun alanlarının trafik bölgelerine yakın olması zayıf yönleri oluşturmaktadır.

\subsection{Veri Toplama ve Değerlendirme}

Çalışmada kentsel doku içerisinde yer alan Sahil Parkı'nın tanımlandırılmasında kullanıcıların rekreasyonel kullanım tercihleri, memnuniyet değerlendirmesi ve alan kullanım sıklığını inceleyen 4 ana parametre kullanılmıştır. Birinci parametre olarak kullanıcıların Rize Sahil Parkı içerisinde ziyaret ettikleri park alanları Altman ve Zube 1989 [15]'un park kriterini içeren (aktivite ve kullanımlar, ulaşılabilirlik, konfor ve imaj, sosyallik) 4 farklı parametreye göre değerlendirilmiştir. Bu parametrelerin her biri kullanım tercihlerine göre aktivite ve kullanımlar (spor yapmak için, kitap okumak için, çocuk oyun alanı için, bisiklet turu için), ulaşılabilirlik (yürümek için, geçiş güzergâhı olduğu için, yol sirkülasyonu), konfor ve imaj (temiz hava almak için, güneşlenmek için, deniz manzarası için, doğası için), sosyallik (arkadaşlarımla dolaşabilmek için, aile veya arkadaş grupları ile bir şeyler yapabilmek için, yeni insanlarla tanışmak için) şeklinde sınıflandırılarak değerlendirmeye alınmıştır.

İkinci parametre olarak, kullanıcı memnuniyet kriterleri [16] yüzde analizi yöntemi ve korelasyon analizi ile, üçüncü parametre olarak, alan kullanım sıklığı, yüzde analiz yöntemi kullanılarak değerlendirilmiştir. Bu parametrelerin değerlendirilmesinde anket formları kullanılmıştır. Anket çalışmaları rekreasyonel alan kullanımlarının başladığı 2018 yılının Mayıs-Haziran ayları arasındaki dönemde yapılmıştır. Verileri toplama aşamasında kullanılan anket yönteminde örnek büyüklüğünün kapasitesi Özdamar 2003 [17]’ deki formüle göre hesaplanmıştır.

$$
n=\frac{N \cdot P \cdot Q \cdot Z_{\alpha}^{2}}{(N-1) \cdot d^{2}}
$$

$\mathrm{N}$ : Evren birim sayısı, n: Örneklem büyüklüğü

P: Evrendeki X'in gözlenme oran1, Q (1-P): X'in gözlenmeme oranı

$\mathrm{Z} \alpha: \alpha=0.05,0.01,0.001$ için $1.96,2.58$ ve 3.28 değerleri

$\mathrm{d}=$ Örneklem hatası

Formül sonucunda Rize merkez bölgesinde yapılan çalışma için N (Evren Büyüklüğü) merkez nüfusu olan 147.317 (Rize 2017 merkez nüfusu, [18] ) alınmıştır. d=01 (örneklem hatası) için örneklem büyüklüğü 96 kişi olarak hesaplanmış olup bu büyüklükten yola çıkarak çalışma anketleri korelasyon analizinde elde edilen sonuçlarda ki hassasiyet derecelerini artırmak için 190 alan kullanıcısına yapılmıştır.

Hazırlanan anket formları ve tablolardan çıkan sonuçlar kullanıcı memnuniyetlerine göre değerlendirilmiştir. Verilerin istatistiksel değerlendirilmesi aşamasında ise kullanıcıların sosyo-demografik durumları (cinsiyet, yaş, medeni durum, eğitim durumu, kullanıcı grubu ), ve kullanıcı memnuniyetlerine ilişkin parametreler (alan kullanım amacı, kullanım sıklığı, ulaşım şekli, alanda geçirilen zaman, güven-güvensizlik durumu, bakım ve yönetim durumu, 
beklentileri vb) arasında korelasyon analizi yapılarak Spearman katsayıları (r) ve önem dereceleri belirlenmiştir. Yapılan istatiksel analizlerde SPSS (Statistical Package for the Social Sciences) 16.01 paket programı kullanılmış olup anketlerden elde edilen bazı veriler \% analiz yöntemi ile tablolar ve grafiklerle değerlendirilmiştir.

\section{Bulgular}

Çalışmada elde edilen bulgular kullanıcıların Rize kentsel kıyı şeridi rekreasyonel kullanım tercihlerinin ve memnuniyetinin değerlendirilmesi ile alan kullanım sıklığının irdelenmesini içermektedir.

\subsection{Rize Kentsel Kıyı Şeridinin Rekreasyonel Kullanım Tercihleri Arasındaki İlişsiler}

Rize kentsel kıyı şeridi Sahil Parkı içerisinde yer alan rekreasyonel alanların karakteristikleri Altman and Zube (1989)'un geliştirmiş olduğu kriterlerine (aktivite ve kullanımlar, ulaşılabilirlik, konfor ve imaj, sosyallik) göre değerlendirilmiştir. Bu kriterlerin her biri alanın kullanımına yönelik kendi içerisinde tanımlanan farklı alt başlıklar altında değerlendirilmiştir. Bu amaçla yapılan \% analiz değerlendirme sonuçları Tablo 1' de verilmiştir.

\begin{tabular}{|c|c|c|c|c|}
\hline \multirow{6}{*}{ 我事 } & & & $\%$ & Tanım / En çok tercih edilen \\
\hline & & Spor yapmak için & 38 & \multirow{5}{*}{$\begin{array}{l}\text { Çalışma alanı farklı rekreasyonel olanaklara sahiptir. } \\
\text { Alanın farklı bölgelerinde çocuk oyun alanları ve } \\
\text { spor alanları mevcutken bisiklet için özel bir parkur } \\
\text { mevcut değildir. Aktivite ve kullanım acısından:spor } \\
\text { yapma etkinliği \%38 oranla en çok tercih edilen } \\
\text { aktivite olmuștur. }\end{array}$} \\
\hline & & & & \\
\hline & End & Kitap okumak için & 8 & \\
\hline & & Çocuk oyun alanı için & 15 & \\
\hline & & Bisiklet turu için & 12 & \\
\hline \multirow{3}{*}{ 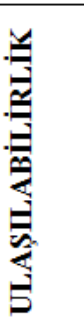 } & & Yürümek için & 78 & \multirow{3}{*}{$\begin{array}{l}\text { Alan içerisinde ulaşım aksını yönlendirici birçok yol } \\
\text { bulunmaktadır. Ulaşılabilirlik açısından kişilerin } \\
\text { alanı kullanım amacı ; \%78 oranla yürümek için } \\
\text { olup, \%9'luk kesim ise geçiş güzergâhı olduğu için } \\
\text { tercih etmektedir. }\end{array}$} \\
\hline & & Geçiş güzergâhı olduğu için & 9 & \\
\hline & & Yol sirkülasyonu & 2 & \\
\hline \multirow{4}{*}{ 車 } & & Temiz hava almak için & 42 & \multirow{4}{*}{$\begin{array}{l}\text { Kentin rekreasyonel ihtiyacını karșılayan çalıșma } \\
\text { alanı kentin nefes noktası durumundadır. Kullanıcılar } \\
\text { çalısma alanını } \% 42 \text { oranla temiz hava almak } \\
\text { için, } \% 40 \\
\text { oranla deniz manzarası için kullanmaktadır. }\end{array}$} \\
\hline & & Güneşlenmek için & 3 & \\
\hline & & Deniz manzarası için & 40 & \\
\hline & & Doğası için & 5 & \\
\hline \multirow{3}{*}{$\underset{\substack{3 \\
0}}{3}$} & & Arkadaşlarımla dolaşabilmek & 39 & \multirow{3}{*}{$\begin{array}{l}\text { Kullanıcılar alanı \%48 oranla aile veya } \\
\text { arkadas grupları ile kullanmaktadır. }\end{array}$} \\
\hline & & $\begin{array}{l}\text { Aile veya arkadaș grupları ile } \\
\text { Bir șeyler yapabilmek için }\end{array}$ & 48 & \\
\hline & jü & Yeni insanlarla tanıșmak için & 6 & \\
\hline
\end{tabular}

Tablo 1 . Rize Sahil Şeridi rekreasyonel kullanım tercihleri arasındaki ilişkiler 
Kullanıcıların değerlendirmeleri dikkate alındığında \%38'lik oranla spor yapma aktivite ve kullanım kriterinde en çok tercih edilen kullanım türünü oluştururken bu kullanım şeklini \%15'lik oranla çocuk oyun alanı, \%12'lik oranla bisiklet turu ve \%8'lik oranla kitap okuma etkinliği takip etmektedir. Kullanıcıların \%27'si'nin belirlenen aktivite ve kullanım tercihlerinden hiçbirini tercih etmediği görülmüştür. Bu değerlendirmeleri; ulaşılabilirlik kriterinde \%78'lik yürüme etkinliği, \%9'luk geçiş güzergâhı ve \%2'lik yol sirkülasyonunu tercih ederken, \%11'lik kullanıcı oranı hiçbirini tercih etmemiştir. Konfor ve imaj parametrelerinde kullanıcılar alanı \%42’lik oranla temiz hava, \%40‘lık oranla deniz manzarasını seyretmek için kullanmaktadır. Alanın sosyallik parametresinde kullanıcıların \%48'lik oranı alanı aile veya arkadaş grupları ile etkinlik gerçekleştirmek için tercih ettiği görülmüştür.

\subsection{Rize Kentsel Kıyı Şeridi Rekreasyonel Alan Kullanıcılarının Memnuniyet Değerlendirmesi}

Rize kentsel kıyı şeridi rekreasyonel alan kullanıcılarının memnuniyetleri değerlendirilirken, alan kullanıcılarının sosyo-demografik yapıları kullanıcı profillerinin orantılı bir şekilde dağıtılması için dikkate alınmış olup, sosyo-demografik yapılardan çıkan pozitif ve negatif yönlü anlamlı ilişkilere Tablo 2'de yer verilmeyerek, bazı sonuçlar metin içerisinde yorumlanmıştır.

Korelasyon analizinde Diğer sorularla anlamlı ilişkisi bulunmadığı için tabloda "Cinsiyetiniz", "Yaş gurubunuz?”, “Medeni durumunuz?”, “Eğitim durumunuz?”, “Kullanıcı grubunuzu seçiniz”, “En çok hangi zamanda alanı kullanmayı tercih edersiniz?”, “Gün içerisinde hangi zamanda alanı kullanmayı tercih edersiniz?” sorularına yer verilmemiş olup, bu soruların değerlendirmesi \% değer olarak verilmiştir.

Ankete 84 kadın (\%44), 106 erkek (\%56) kullanıcı katılmıştır. Sosyo-demografik yapı içerisinde değerlendirmeye alınan “cinsiyet” faktörü ile "alanda ne kadar zaman geçiriyorsunuz?” ve “ alanı gece kullanımınızda kendinizi güvende hissediyor musunuz?” sorularıyla negatif yönlü anlamlı bir ilişki bulunmaktadır. Kadın kullanıcılar alanda daha fazla zaman geçirmek isterken $\left(\mathrm{r}=-, 145^{*}\right)$, Park alanını gece kullanırken kendilerini güvende hissetmemektedirler $(\mathrm{r}=-, 230 * *)$.

Kullanıcıların yaş grupları değerlendirildiğinde kullanıcıların yaşı arttıkça alan kullanımları azalmakta $\left(\mathrm{r}=, 277^{* *}\right)$, alana ulaşım şekilleri araçla olmaktadır $\left(\mathrm{r}=, 240^{* *}\right)$. Yaş faktöründe ele alınan değerlendirmeler kullanıcıların medeni durumlarıyla da paralellik göstermektedir. Kullanıcıların eğitim seviyesi arttıkça; ulaşımı araçla sağlamakta $(\mathrm{r}=, 182 *)$, alanı temiz bulmamakta $(\mathrm{r}=, 152 *)$, alanın iyi yönetildiğini düşünmemekte ( $\left.\mathrm{r}=, 257^{* *}\right)$, çocuk oyun alanları, donatı elemanları ve açık yeşil alanları yetersiz bulmakta $\left(\mathrm{r}=, 262^{* *} ; \mathrm{r}=, 146^{*} ; \mathrm{r}=, 217^{* *}\right)$, bitkisel tasarımı işlevsiz bulmakta $\left(\mathrm{r}=, 149^{*}\right)$ kentin denize bakan ön cephesindeki binaların sahil görüntüsünü kapatması nedeniyle $\left(\mathrm{r}=, 235^{* *}\right)$ bu alanları kent parkları ile ilişkili bulmamaktadır $\left(\mathrm{r}=, 152^{*}\right)$.

Kullanıcıların eğitim seviyelerinin artması ile çalışan kullanıcı kesimi arasında benzer ilişkiler tespit edilmiş olup ( $\left.\mathrm{r}=, 158^{*} ; \mathrm{r}=, 162^{*}\right)$ donatı elemanları yetersiz ve alan kent parkları ile ilişskisiz bulunmuştur.

Kullanıcılar rekreasyonel kullanım yoğunluğu fazla olan alanlarda kendilerini güvende hissetmekte $(\mathrm{r}=, 152 *)$, gerçekleştirdikleri aktivite kullanımlarına yönelik donatı elemanlarını yetersiz bulmaktadırlar ( $\left.\mathrm{r}=, 190^{* *}\right)$.

Alan kullanım sıklığı az olan kullanıcıların alana ulaşım şekilleri araçla $\left(\mathrm{r}=, 200^{* *}\right)$, kalabalık bir grupla $(\mathrm{r}=, 173 *)$ kullanırken, kullandıkları rekreasyonel alanları güvenli bulmamakta $\left(\mathrm{r}=, 168^{*}\right)$, ve bu alanların gece kullanımında kendilerini güvende hissetmemektedirler $\left(\mathrm{r}=, 212^{* *}\right)$. 
6Alanı hangi amaçla kullanyorsunuz? 1: Geç̧̧ amaçli, 2:Dinlenmmek için, 3:Yeme içme için,

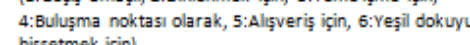
7.5erilen bu

2:Haftada iki, 3: Haftada bir, $4: 15$ günofs bir, 5:Ayda bir 6:Nadiren]

10.Alanda ne kadar zaman geçiryorsunuz? (1:30 gkk gan az 2:30-60 olk arass, 3:1-2,5 saat arass, 4:2,5 saatten fazla)

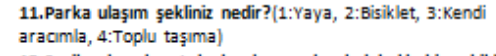

mi kullanmayı tercih edersiniz? (1:Tek, 2:Grup, 3:Digierer) 13.Alanı gündüry kullanmimnnzda kendinizi güvende hissediyor musunuz? (1:Hissediyorum, 2:kismen,

3:Hissetmiyorum]

14.Alanı gece kullanımınıda kendinizi güvende hissediyor musunuz?[1:Hissediyorum, 2:Ksismen, 3:Hissetmiyorum) 15.Kendinizi güvende hissetmedig̈iniz bir alan var m?? [1:A $2: B, 3: G, 4: D, 5: E, 6: F, 7: 6,8: H$

uz? (1:Evet, 2:Hayrr)

17. Cevabinı hayrr ise en çok dikkatinizi çeken kirrilik nedir? (1:Cékirdek kabuklarl, 2:Deniz kylsindaki kirlilik, 3:Yesil alanlardaki kirlilik, 4:Donatların kullanımında

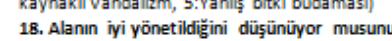
(1:Evet, 2:Hayr)

19. Alanda en çok eksik gördüğünüz mekânlar/detaylar dir? (1:5por alanlarl, 2:Suyun görsel ve oyun amaç,

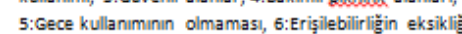
7:Kı́s mevsiminde kullanima uvgun mekânlarin bulunmamas!)

20. Alanda çocuk oyunlarını ve spor alanlarııı yeter bullyor musunuz? (1:Evet, 2:Hayr)

21. Açik yeşil alanlarını yeterli buluyor musunuz? (1: Eve 2:Hayrl

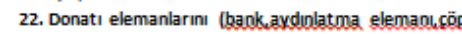
kutusu vb.) yeterli buluyor musunuz? (1:Evet, 2:Hayrr) 23. Donatı elemanlarinı bakimlı ve düzenli bullyor muzunuz? (1:Evet, $2:$ Hayir,

24. Alanın bitkisel tasarımı sizi etkiliyor mu? [1:Evet, 2:Hayir)

25. Alandaki bitkisel tasa
musunu?? (1: Evet, 2:Hayu

26. Alanda en sok begondǐiniz nokta?

[1:A, 2:B, 3:G, $4: D, 5: E, 6: F, 7: G, 8: H)$

27. Bu parkı kent parklar ile iliskili buluys

musunuz?[1:Evet, 2:Hayrr]

28. Cevabin

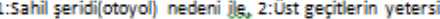

Olması nedeniyle, 3:Kentin denize bakan ön cephesinde.

Gimalarin sahi goorüntususunu kapatması nedeni ile

.

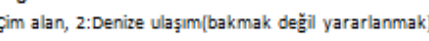

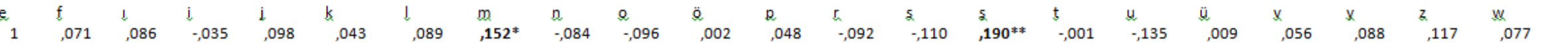

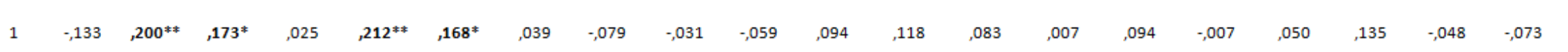

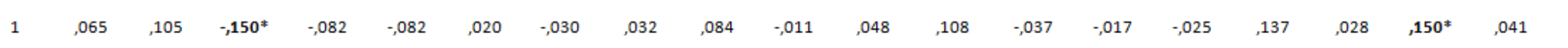

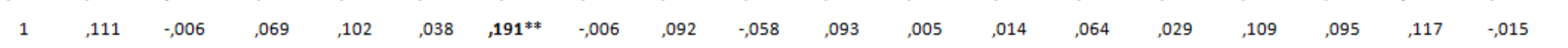

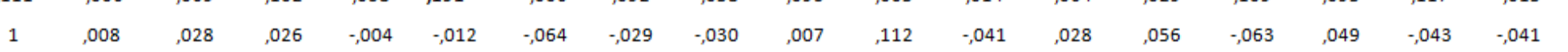

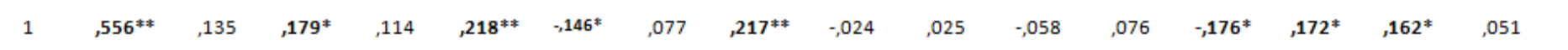

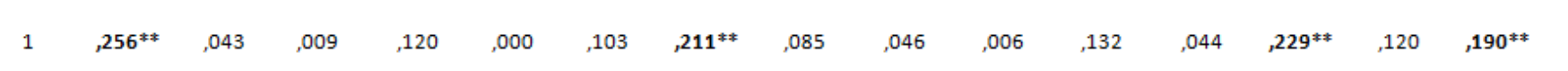

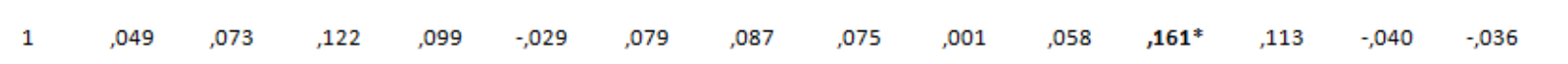

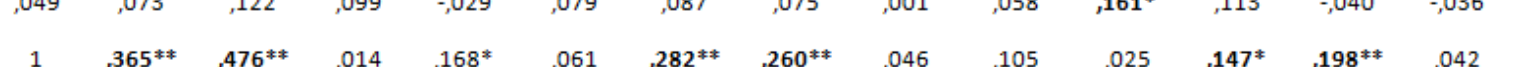
$\begin{array}{lllllllllllll} & \mathbf{1 6 4 *} & \mathbf{1 6 4} & 046 & -, 040 & , 088 & , 133 & , 093 & , 008 & -, 003 & -, 048 & , 032 & , 121\end{array}$

$1 \quad-, 062 \quad, 310^{* *} \quad, 192^{* *} \quad, 240^{* *} \quad, 190^{* *} \quad, 100 \quad, 232^{* *} \quad, 044 \quad, 284^{* *} \quad, 224^{* *} \quad 051$

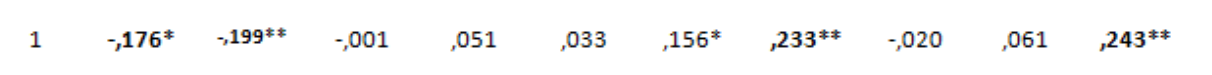

$\begin{array}{llllllllll} & , 237^{* *} & , 102 & , 146^{*} & , 184^{*} & , 138 & , 020 & , 232^{* *} & .097 & -131\end{array}$

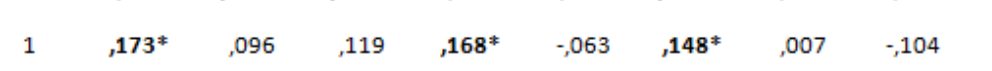

$1 \quad, 424^{* *}, 191^{* *} \quad, 368^{* *} \quad, 125 \quad, 293^{* *} \quad, 184^{*} \quad, 021$

$1 \quad, 191^{* *} \quad, 276^{* *} \quad 092 \quad, 252^{* *} \quad, 125 \quad-, 044$

$1 \quad, 215^{* *} \quad, 025 \quad, \mathbf{1 8 4}^{*} \quad, 117 \quad-, 017$

$1 \quad, 086 \quad, 234^{* *}, 146^{*} \quad 050$

$\begin{array}{llll}1 & , 036 & -, 010 & -, 031\end{array}$

$1 \quad, 618^{* *}-, 009$

$1 \quad, 109$

Tablo 2. Çalışma alanı ve çalışmada kullanılan bölgeler 
Alanda uzun süre vakit geçiren kullanıcılar gündüz kullanımlarında kendilerini güvende hissetmekte olup (r=,150*), kentte ki diğer parklarla ve kentin denize bakan ön cephesindeki binaların sahil görüntüsünü kapatması nedeniyle ilişkili $\left(\mathrm{r}=, 150^{*}\right)$ bulmamaktadır.

Kullanıcılara sorulan 'Alanı temiz buluyor musunuz?' sorusu (o, ö, r, ş, t, y, z,) soruları ile pozitif yönde anlamlı ilişkiler içermekte $\left(r=, 365^{* *} ; \mathrm{r}=, 476^{* *} ; \mathrm{r}=, 168^{*} ; \mathrm{r}=, 282^{* *} ; \mathrm{r}=, 260^{* *} ; \mathrm{r}=147^{*} ; \mathrm{r}=, 198^{* *}\right)$ olup, yukarıdaki sonuçlarla benzerlik göstermektedir.

Kullanıcılara yapılan anket çalışmasında kullanıcıya sorulan fakat korelasyon analizi ile sorgulanmayan diğer sorulara , \% analiz yöntemi uygulanmıştır. Kullanıcıların “Alanda en çok dikkatinizi çeken kirlilik nedir?” sorusuna verdikleri cevaplar sırasıyla; \%52 oranla çekirdek kabukları, \%22 oranla deniz kıyısındaki kirlilik, \%11 ise yeşil alanlardaki kirlilik şeklinde sıralanırken bu tercihleri \%10 oranla donatıların kullanımından kaynaklı vandalizm ve \%2 oranla yanlış bitki budaması tercihleri takip etmektedir.

“Alanda en çok eksik gördüğünüz mekân/detay nedir” sorusuna verilen yanıtlar tercih sırasına göre; \%30 spor alanları, \%16 bakımlı piknik alanları ve \%10 kış mevsimi kullanımına uygun alan ihtiyacından oluştuğu görülmektedir.

Sahil Parkı'nın kent parkları ile ilişkili olmamasında ki en büyük sebep \%49 oranla sahil şeridi (otoyol), \%18 oranla üst geçitlerin yetersiz olması, \%9 oranla kentin denize bakan ön cephesindeki binaların sahil görüntüsünü kapatmasıdır. “Alana yeni bir tasarım yapılmasında kullanıcıların istedikleri tasarımlar nedir?” sorusu \% 40 çim, \%23 denize ulaşım (işlevsellik kazandırmak) ve \%15 ile bitki koridorları şeklindeki verilen cevaplarla sıralanmaktadır.

\subsection{Rize Kentsel Kıyı Şeridi Alan Kullanım Sıklığının Değerlendirilmesi}

Rekreasyonel alanların kullanım sıklığı alan kalitesini etkileyen en önemli kriterlerden birini oluşturmaktadır. $\mathrm{Bu}$ nedenle kullanımlar değerlendirilirken hafta içi ve hafta sonu, sabah-öğle ve akşam saatleri olmak üzere değerlendirmeler yapılmıştır. Alan kullanıcıları \%50 oranla müsait oldukları her an alanı kullanmayı tercih ederken, \%45'i hafta sonu kullanımını tercih etmektedir.

Kullanıcıların gün içerisindeki kullanım saatlerinin \%54'ü akşam saatlerini, \%32'si öğleden sonraları kullanmayı tercih ederken, sabah ve gece saatlerinin pek tercih edilmediği (\%3) görülmüştür. Kullanıcıların \%53’ü alanda 1-2,5 saat zaman geçirmekte olup, kullanıcıların \%63'ü yaya, \%25'i kendi araçlarıyla, \%7'si toplu taşıma ile ve $\% 2$ 'si bisiklet ile ulaşım sağlamaktadır.

A:Alanın gün içerisinde kullanım sıklığı grafiği, S: Sabah \%4, Ö: Öğle \%5, ÖS: Öğleden sonra \%31, A: Akşam \%54, G: Gece \%5 Kullanıc1 tercih oranı (\%)

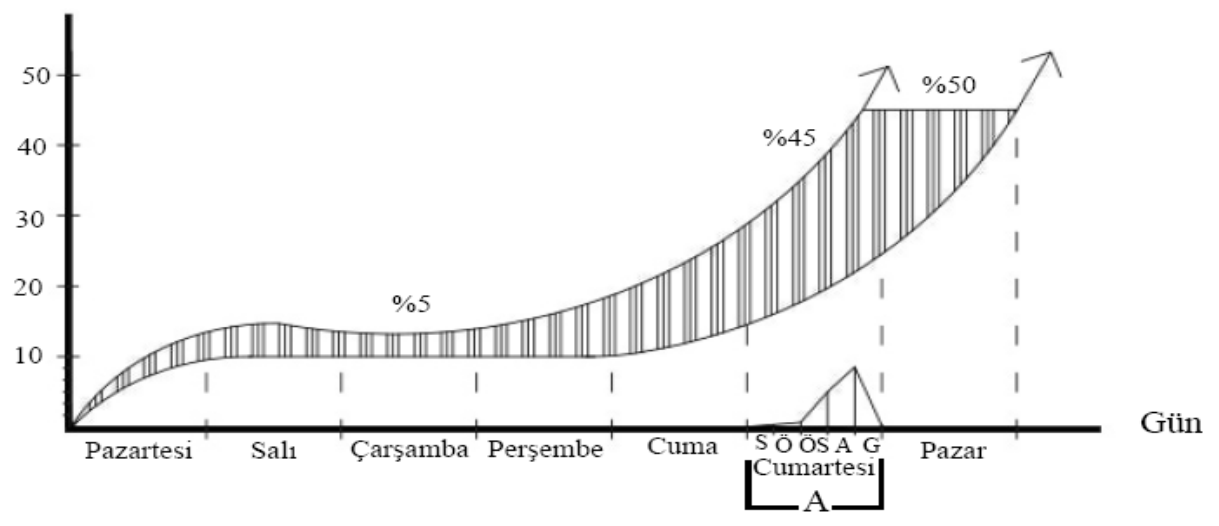

Şekil 2 . Çalışma Alanı kullanım sıklığı/Zaman grafiği 


\section{Sonuç ve Öneriler}

Yaşamı fiziksel ve psikolojik olarak daha rahat kılmak ve ihtiyaçlara daha uygun ortamlar oluşturmak için tasarlanan yeşil alanlarda, kullanıcı ihtiyaçlarını önceden kestirmek ve açık yeşil alanlarda oluşturulacak çevreyi bu ihtiyaçlara göre şekillendirmek gerekmektedir. Bu nedenle kullanıcı istek ve ihtiyaçları, rekreasyonel alanların hizmet kalitesinin değerlendirilmesinde etkin parametreler haline dönüşmektedir. $\mathrm{Bu}$ parametreler aynı zamanda yeni rekreasyonel alanların oluşturulmasında yönlendirici etkide yapmaktadır. Oluşturduğu kullanıcı profili ve isteklerine bağlı oluşan yönlendirici etkiye göre rekreasyonel alanların içindeki etkinliklerin oluşturulması, hizmet anlamında çevresine olan katkısı veya kullanıcıların tatmin dengesinin oluşturulmasında kullanılmalıdır.

Rize kentsel kıyı şeridi rekreasyonel alanı kültürel peyzaj karakterleri olarak bireylere farklı özelliklere sahip yeşil alan kullanımları sunmaktadır. Rize kentinin geleneksel dokusunu yansıtacak şekilde düzenlenen bu yeşil alanlar birbirlerine yakın ve küçük alanlardan oluşarak farklı tercihleri bir araya getirmektedir.

Bernasconi et al. tarafindan 2009'da görsel kalite analizine yönelik yapılan çalışmada bitkisel dokunun (ağaçlar ve çim alanlar) kentsel manzara kalitesini artırdığı belirtilmiş olup [19], Rize ilinde yapılan çalışmayla benzerlik göstermektedir. Yeşil alanların bireyler üzerinde uyandırdığı memnuniyet, kullanım sıklığı, yeşil alanlara yakınlık ve refah düzeyi ile ilişkili olup [20], yapılacak tesislerin türü ve özellikleri ile doğrudan doğruya bağlantılıdır. Rekreasyonel düzenleme süreçlerindeki kullanıcı memnuniyeti, hizmet kalitesi ve memnun kalma seviyesi planlama süreçlerine etki eden parametrelerin bu doğrultuda düzenlenmesi ve uygulanması ile mümkündür [21]. Bu doğrultuda ele alınan bu çalışmada;

Polat (2012)'ın yaptığı çalışmada, kent parklarında yer alan canlı ve cansız tasarım öğelerinin doğallık derecelerinin görsel peyzaj kalitesi üzerine pozitif yönde önemli katkısı olduğu sonucuna varılmıştır [22]. Kullanıcılar alandaki donatı elemanları ve malzeme kullanımlarını çevreye uyumsuz bulmaktadır. Bu nedenle Sahil Parkı'ndaki donatı elemanlarının kullanımında tamamen doğal ve yerel dokuya uygun tasarımlar geliştirilerek düzenli bakımları sağlanmalıdır. Kullanıcılar için donatıların doğal görünümleri ve bakımlarının yanı sıra güvenli oluşları da oldukça önemlidir.

Donatı elemanları kullanıcıların ihtiyaçlarını karşılayacak sayı ve niteliğe sahip olmamakla birlikte zamansal deformasyonunun yanı sıra yanlış ve özensiz kullanımlarından dolayı Rize Sahil Parkı bakımsız görünmekte, kullanıcılarda bu durumdan şikâyet etmektedirler. Yavuz, 2010 [23], yaptığı çalışmada, kentsel açık alanlarda problem olarak görülen vandalizm eyleminin kent parklarında etkili olduğunu ve sonuç olarak parkların görsel kalitesini azalttığını tespit etmiştir. Bu nedenle rekreasyonel alanların bakımına özen gösterilmeli, alan kullanıcıları da bu konuda bilinçlendirilmelidir.

Çalışma alanındaki bitkilendirme tasarımının fonksiyonel ve estetik yaklaşımlardan uzak olduğu görülmektedir. Bu durum alan içerisinde yapılacak rehabilitasyon çalışmaları ile (bitki budaması-bakımı, mevcut bitki kullanımı vb.) düzenlenebilir. Bitkilendirme tasarım eksikliği Rize Mimari ve Estetik Komisyonu tarafından tespit edilerek rekreasyonel park alanlarına Vaccinium corymbosus, Citrus sp. Citrus sinensis, Citrus reticulata ve Tilia cordata desteği sunulmaktadır.

- Kullanıcıların alan kullanım süreleri ve zaman dilimleri dikkate alınarak etkinlikler planlanmalıdır.

- Denizin görsel niteliğinin yanı sıra aktif rekreasyonel kullanımlarla desteklenerek, su sporları ve plaj alanları tasarlanmalıdır.

- Alandaki aydınlatma sistemi geliştirilerek gece kullanımlarında güvenlik ihtiyacı sağlanmalıdır.

- Yaya yürüyüş yolları ile bisiklet yolu ayrılmalı, bisiklet için ayrı bir parkur oluşturulmalıdır. 
- Kent parklarında bulunan çocuk oyun alanları, çocukların rekreasyonel ihtiyaçlarını karşılamanın yanı sıra öğrenmelerine de katkı sağlayan açık alanlar olup, bu açık alanlar çocukların öğrenme sürecine katkı sağlayacak şekilde tasarlanmalıdır [24].

Kentlerimizdeki açık yeşil alanların önemli bir kısmı estetik kaygılar içeren tasarımlardan oluştuğu için doğadan ve genel döngüsünden kopuk, ekolojik, kaygılardan uzak bir şekilde planlanmaktadır. Oysaki büyük kaynaklar aktarılarak planlanan açık-yeşil alanlar, ekolojik ve finansal olarak sürdürülebilir tasarım yaklaşımlarına dönüştürülebilir [25].

Özhancı ve Yılmaz (2011) yaptı̆̆ı çalışmada görsel peyzaj kalitesi ile yakından ilişkili olan peyzaj yapısının rekreasyon alanlarının tercih edilmesinde ve görsel peyzaj karakterinde önemli bir rolü olduğunu belirtmiştir [26]. Sonuç olarak kent içi veya kentsel kıyı şeridi rekreasyonel alanları, kültürel ve doğal yaklaşım doğrultusunda planlandıkları sürece, kent sakinlerinin rekreasyonel gereksinimlerini karşılamada etkili ve yeterli birer kaynak olacaklardir.

\section{Kaynaklar}

[1] Bogenç, Ç., “Dünya Mirası Safranbolu Alan Yönetim Planının Geliştirilmesine Yönelik Bir Çalışma” Bartın Üniversitesi, Fen bilimleri Enstitüsü, Doktora Tezi, Bartın, 169s, 2016

[2] Chiesura, A., “The role of urban parks for sustainable city” Landscape and Urbun Planning, 68, 129-138, 2007

[3] Loures, L., Santos, R., Panagopoulos, T., "Urban parks and sustainable city planning - The case of Portimão. Portugal” Wseas Transactions On Environment And Development, 10(3), 171-18, 2007

[4] Sakıcı, Ç., "The assessment of the relationship between various waterscapes and outdoor activities: Edirne, Turkey” Environmental Monitoring And Assessment, 186(6), 3725-3741, 2014

[5] Jaafar, N., Tudin, R., "UPARQUAL: The development of an urban park satisfaction measurement scale” International Journal of Business and Society, 11(2),17-34, 2010

[6] Stanis, S. A., Schneider, I. E., Anderson, D. H., "State park visitors' leisure time physical activity, constraints, and negotiation strategies” Journal of Park and Recreation Administration, 27(3), 21-41, 2009

[7] Bekci, B., Taşkan, G., Bogenç, Ç., Dinçer D., “Ekolojik Peyzaj Tasarım Hedefinde Ergonomik Tasarım Yaklaşımları” Balıkesir Üniversitesi 19. Ulusal Ergonomi Kongresi, Balıkesir, 2013

[8] Tonge, J., Moore, S. A., Taplin, R., ”Visitor satisfaction analysis as a tool for park managers: a review and case study” Annals of Leisure Research, 14(4), 289-303, 2011

[9] Uysal, M., Eser, Z., Birkan, I., “Measuring Visitor Satisfaction: An Outdoor Recreational Setting” TTRA’s 33rd Annual Conference Proceedings, 23-27 June, 279-284 s, Arlington, USA, 2002

[10] Polat, A. T., “ Kent parklarında görsel kalite ve doğallık derecesi arasındaki ilişkilerin belirlenmesi” I $\breve{g} d \boldsymbol{r}$ Üniversitesi Fen Bilimleri Enstitüsü Dergisi, 2(3):85-92, 2012

[11] Roovers, P., Hermy, M., Gulinck, H., "Visitor Profile Perceptions and Expection in Forests From A Gradient of Increasing Urbanisation in Central Belgium” Landscape and Urban Planing, 59:129-145, 2002

[12] Kozak, M., Rimmington, M., “Tourist satisfaction with Mallorca, Spain, as an off-season holiday destination” Journal of Travel Research, 38 No. 3, 2000

[13] Aksoy, Y., Aygün, B., Turan, A. Ç., Ören, L., “Fatih İlçesinde Risk ve Afet Yönetimi Kapsamında Mevcut ve Öneri Yeşil Alanların Deprem Öncesi ve Sonrası Değerlendirilmesi Risk Yönetim Çerçevesinde Yeşil Koridor 
Dönüşüm Projesi” İBB/Y ve KD-IŞAT MÜDÜRLÜĞÜ, Yüklenici: BİMTAŞ A.Ş, Alt Yüklenici (Proje Yüklenici): Bahçeşehir Üniversitesi, 2008

[14] Volkan, Ö., Orcid, A., Kılıç, C., "Altındere Vadisi Milli Parkı kullanıcılarının rekreasyonel memnuniyetini etkileyen faktörlerin belirlenmesi" Ormancılık Araşttrma Dergisi, 30-45, 2017

[15] Altman, I., Zube, E. H., "Public places and spaces" Springer Science \& Business Media, 315 s, 1989

[16] Yılmaz, H., Yılmaz, S., Yıldız, N. D., "Kars Kent Halkının Rekreasyonel Talep ve Eğilimlerinin Belirlenmesi" Atatürk Üniversitesi Ziraat Fakültesi Dergisi, 34(4), 2003

[17] Özdamar, K., "Modern bilimsel araştırma yöntemleri" Kaan Kitabevi, 228s, Eskişehir, 2003

[18] URL 1 : https://www.nufusu.com/ilce/merkez_rize-nufusu,2018

[19] Bernasconi, C., Strager, M. P., Maskey, V., Hasanmyer, M., "Assessing public preferences for design and environmental attributes of an urban automated transportation system" Landscape and Urban Planning, 90: 155-167, 2009

[20] Yilmaz, S., Duzenli, T., Dincer, D., "Evaluation Of Factors Related To Well-Being Effects Of Urban Green Spaces On Users" Fresentus Environmental Bulletın, 26(12 A), 174-185, 2017

[21] Onsekiz, D., Emür, S. H., "Kent parklarında kullanıcı tercihleri ve değerlendirme ölçütlerinin belirlenmesi" Erciyes Üniversitesi Sosyal Bilimler Enstitüsü Dergisi, 1(24), 69-105, 2008

[22] Polat, A. T., "Kent Parklarında Görsel Kalite ve Doğallık Derecesi Arasındaki İlişkilerin Belirlenmesi" I ğdır Üniversitesi Fen Bilimleri Enstitüsü Dergisi, 2(3), 85-92, 2012

[23] Yavuz, A., "An experimental study on vandalism: Trabzon Parks" Scientific Research and Essays, 5(17), 2463-2471, 2010

[24] Acar, H., "Learning environments for children in outdoor spaces" Procedia-Social and Behavioral Sciences, 141, 846-853, 2014

[25] Bekci, B., Bogenç, Ç., Taşkan, G., "Karabük Üniversitesi Kampüs Alanında Yapılan Çevre Düzenleme Çalışmalarında Kullanılan Yerli ve İthal Abies sp. Türlerinin İklim Şartları ve Toprak Koşulları Karşısındaki Dayanıklılığının Araştırılması” Karadeniz Fen Bilimleri Dergisi, 4(11), 25-34, 2013

[26] Özhanc1, E., Yılmaz, H., "Rekreasyon Alanlarının Görsel Peyzaj Kalitesi Yönünden Değerlendirilmesi; Erzurum Örneği’'Iğdır Üniversitesi Fen Bilimleri Enstitüsü Dergisi, 1(2), 67-76, 2011

\section{Extended Abstract}

\section{İntroduction}

Coastal areas and coastlines are important natural resources to meet the increasing recreational needs of individuals. These areas are preferred as settlements and recreation areas due to their easy accessibility, rich resource potential and psychological impact on individuals. Coastlines, which have a linear structure, provide the spatial continuity of landscapes, textures and recreational areas that spread within this silhouette. Due to the difficulties arising from the inclination of the existing topography of the Black Sea region, the importance of recreational use of the coastline is increasing, and the need for open space is demanded.

In this study, user demands and satisfaction situations in the recreational areas of the central coastline of Rize province were discussed and user satisfaction and demands were questioned by using surveys. In order to make life more physically and psychologically comfortable and to create more suitable environments for the needs, it is necessary to predict the needs of the users arising from their physical, physiological, psychological and social structure and to shape the environment consisting of open spaces according to these needs. It is becoming increasingly important to make appropriate planning decisions in order to meet the expectations and satisfaction of the users in higher quality areas and to improve the quality of recreation experiences. In the light of this study, the user satisfaction level in 
recreational uses of the study area was revealed, deficiencies encountered in designs were identified and various solution suggestions were developed. The aim of this study is to preserve the natural and cultural landscape potential, to provide sustainable development of the study area, and to meet the recreational needs.

\section{Method}

In the study, 4 main parameters that examine the users' recreational use preferences, satisfaction evaluation and frequency of land use were used to define the Coast Park in the urban texture. As the first parameter, the parks visited by the users in Rize Coastal Park were evaluated according to 4 different parameters including the park criteria of Altman and Zube 1989 (activity and uses, accessibility, comfort and image, sociability). Each of these parameters was classified as activities and uses (for sports, for reading books, for children's playground, for cycling tour), accessibility (for walking, for passage route, road circulation), comfort and image (for getting fresh air, for sunbathing, for seascape, for nature), and sociality (for hang out with friends, for doing activities with family or groups of friends, meeting new people) according to the usage preferences and was evaluated. As the second parameter, user satisfaction criteria were evaluated by percentage analysis and correlation analysis, and as the third parameter, the frequency of field use was evaluated using the percentage analysis method. Questionnaire forms were used to evaluate these parameters. The results obtained from the questionnaire forms and tables were evaluated according to user satisfaction levels. For the statistical evaluation of the data, the correlation between the socio-demographic status of the users (gender, age, marital status, educational status, user group), and parameters related to user satisfaction (area usage purpose, frequency of use, mode of transportation, time spent in the area, trust-mistrust status, maintenance and management status, expectations, etc.) was analyzed and spearman coefficients (r) and significance levels were determined.

\section{Results and Discussion}

When the characteristics of recreational areas were examined by the criteria developed by Altman and Zube (1989), it was seen that \%38 of the users preferred to do sports in the criterion of activities and usage, \%78 preferred to walk in the criterion of accessibility, \%42 preferred to get fresh air in the criterion of comfort and image, \%42 preferred to do activities with family or groups of friends in the criterion of sociality. 190 users (44\% are females and 56\% are males) using Rize urban coastline do not find the area clean $\mathrm{r}=, 152 *$, do not think that the area is well managed $r=, 257^{* *}$, find playgrounds, fittings and light green areas inadequate $r=, 262^{* *} ; r=, 146^{*} ; r=, 217^{* *}$, find botanical designs non-functional $r=, 149 *$, and do not find Coast Park to be associated with city parks because the buildings on the front of the city facing the sea close the coastal view $r=, 235^{* *}$. With the results obtained, suggestions were developed for recreational areas of the coastline.

Rize urban coastline recreation area offers individuals the use of green areas with different characteristics. These green spaces, which have been arranged to reflect the traditional texture of the city of Rize, consist of small and close areas, bringing different preferences together. Activities should be planned taking into account the duration of using the area and time periods. The visual quality of the sea should be supported by active recreational uses and therefore water sports and beach areas should be designed. The lighting system in the area should be improved and security needs should be provided during night use. Pedestrian walkways and bicycle path should be separated and a separate track should be created for cycling. Children's playgrounds in urban parks are open spaces that not only meet the recreational needs of children but also contribute to their learning. Therefore, these open spaces should be designed to contribute to children's learning process. 